\title{
Analysis of justification for applying two gear sets within the universal gear reducers
}

\author{
Milan Rackov ${ }^{1,{ }^{*}}$, Siniša Kuzmanović ${ }^{1}$, Ivan Knežević ${ }^{1}$, Maja Čavić $^{1}$, and Marko Penčić ${ }^{1}$ \\ ${ }^{1}$ University of Novi Sad, Faculty of Technical Sciences, 6 Trg Dositeja Obradovića, 21000 Novi Sad, \\ Serbia
}

\begin{abstract}
In the area of universal gear reducers, standard does not prescribe relations between load capacity, gear ratios and axis heights. Therefore, larger load capacity of some gear reducers manufacturers has advantage for lower gear ratio and, vice versa, smaller load capacity of the gearbox achieves higher values of gear ratio. However, there are some manufacturers who produce gear reducers with smaller or larger load capacity for higher or lower gear ratio, within the same axis height. This paper deals with analysis of justification of applying two gear sets, especially in the case when socalled intermediate sizes of gear reducer are not used.
\end{abstract}

\section{Introduction}

Axis heights of universal gear reducers are prescribed according to the standard row R20. Since this row is very dense, for a while manufacturers of universal gear reducer produced reducers with axis height from a standard row R10 (these numbers belong to the standard row $\mathrm{R} 20$ ). But soon they increased axis heights in order to increase gear ratio, and now reducers are produced with axis height in a standard row R20/2. In the area of the most used gearbox sizes, some manufacturers produce so-called intermediate sizes with the axis heights in a row R20.

There is no standard which defines particular load capacities within different sizes (axis heights), so manufacturers have open field for defining load capacities [1].

Load capacity values of leading gear reducer manufacturers are followed, so that particular interchangeability could be provided. In order to achieve some advantage at the market, smaller manufacturers of gear reducers produce reducers with smaller torque capacity, but with higher gear ratios. In this way they are able to provide cheaper lower stage gearbox in particular segment of gear ratios.

However, leading gearbox manufacturers recognized this occurrence, and started to offer two sets of gear pair within the same size, and also even in the same of gearbox housing. With this two gear sets, they provide particular gear ratio for larger and for smaller load capacity, so that they annulled advantage of smaller gear reducer manufacturers [2].

\footnotetext{
* Corresponding author: $\underline{\text { racmil@,uns.ac.rs }}$
} 


\section{Problem description}

Depending of the gear ratio value, there are single-, two-, three- and multi-stage gear reducers. One-stage gear reducers are always assembled in the housing for single-stage gear reducer. However, due to lower demand for these reducers, there are manufacturers which do not produce single-stage gearbox at all, and their gear ratio is replaced by lower gear ratio of more expensive two-stage gear reducer [2-4].

Two-stage gear units can be installed in separate housing for two-stage gear reducer [5], or in the universal housing for two- and three-stage gear reducers [6]. Of course, there are manufacturers which produce both type of housing, two-stage and three-stage gear reducer housing [7]. It is understandable that producing of two-stage gear reducers in special housing for only two-stage gear pairs has slightly lower production costs than using universal housing for two- and three stages of gear pairs.

Three-stage gear reducer can be assembled in universal housing for two- and three-stage gearbox, but also combined of two-stage and single-stage gear unit $[1,5]$. Production costs of three-stage gear reducer assembled in universal gear unit housing are lower than producing the same reducer combined of two-stage and single-stage gear unit. However, there are some manufacturers that rather produce three-stage gear units in this way, combining two-stage and single-stage gear unit, but some manufacturers produce them in both ways $[7,8]$.

Four-stage gear units are usually manufactured combining two-stage gear units. Fivestage gear units are combined of three- and two-stage gear units, etc.

Which concept of gear reducer will be adopted depends on marketing orientation of their manufacturers. The largest gear reducer demand is within the speeds between 20 and $50 \mathrm{rpm}$. For driving with four-pole asynchronous motor, that roughly corresponds to the gear ratio between 30 and 70, which covers higher gear ratio values of two-stage gear units and lower gear ratio values of three-stage gear units $[9,10]$. Until recently it was usual to produce single-stage gearbox with highest gear ratio of about 6.3, two-stage gearbox with highest gear ratio of about 20 and three-stage gearbox with highest gear ratio of about 100 . Today, values of gear ratio are increased, so highest gear ratio for one-stage gearbox is up to 12.5 , for two-stage up to 50 and for three-stage gearbox up to 300 [5, 8]. This increasing of gear ratio has caused the using of simpler (lower-stage) and thus cheaper gearbox. However, it should be noted that gear reducer with the highest gear ratio is always more expensive than gear reducer with some lower gear ratio. It is because of larger axis distance and thus larger diameter of driven gears. Nevertheless, producing of lower-stage gear reducer makes certain savings which compensate increased production costs. Additionally, with increasing gear ratio, some manufacturers succeed to increase maximal load capacity of their gear reducers and in this way to offer cheaper gear units. These interventions of leading gear reducer manufacturers improved their position at the market, but very soon smaller manufacturers have done the same thing. However, there is some reduction of competition at the market since small manufacturers were not be able to financially follow the interventions of major manufacturers, mainly due to the high cost of producing special casting tools $[11,12]$.

\section{Descriptions the ways of solving problems}

Gear ratio of single-stage gear reducer is performed in a standard row R10; only for the reason row R20 needs more gears, but especially driving gears. Since motor gear reducer is usually used, positioning of driving gear is done on shaft of gear unit motor. Each size of electric motor will need different gear because of its different shaft diameter and therefore row R20 is not good for single-stage gear units. Gear ratio of two-, three- and multi-stage 
gear reducer is performed in standard row R20. In that case, two possible gear ratios are added on the first gear pair. Their combination gives two gear ratios and combination of other first gear pairs gives the values of standard row R20 for output gear ratio of the gearbox (Fig. 1) [2, 9, 10].

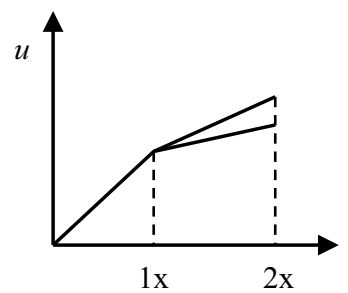

Fig. 1. The way of performing gear ratio for two-stage gear reducer.

Gear ratio of three-stage gear reducer is also offered in standard row R20. These gear ratios can be obtained in two ways. If the output gear pair with higher load capacity is added on two-stage gear reducer, it can be obtained gear ratio in the row R20 (Figure 2-a). The other way is to use the output gear pairs from two-stage solution with inserting a gear pair with lower load capacity as the second and using the first gear pair from a smaller size of gearbox (Figure 2-b). Of course, this is always possible except for the smallest size of gear reducer. Using the first gear pair for smallest size of three-stage gear reducer is not economical since the gears have higher load capacity than it is required $[1,2,9,10]$.

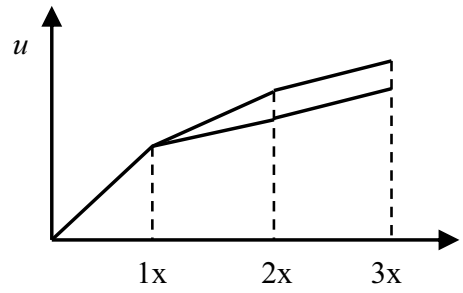

$a$

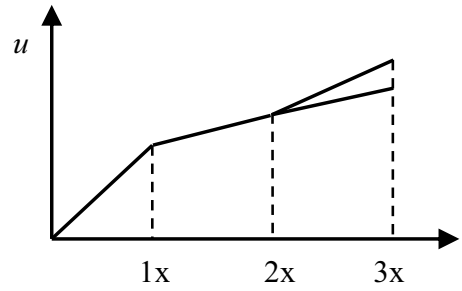

$b$

Fig. 2. The way of performing gear ratio for three-stage gear reducer, (a) with additional output gear pair, (b) with additional lower second gear pair and using the first gear pair from a smaller size of gearbox.

If the first solution is used (Fig. 2.a) with additional third gear pair, the same uniform housing can not be used for two- and three-stage gear reducer. It is because of big difference between load capacities of two- and three-stage load capacity which will increase production costs. Therefore, the other solution with common output gear pair for two- and three-stage gear reducer will be used (Fig. 2.b). This solution provides assembling two and three gear pairs in the same housing, thereby significantly reducing production costs. This approach achieves the same load capacity of two- and three-stage gear reducer (Table 1, Table 2). Therefore it is required to install different sizes of electric motor on the same housing in order to use all available advantages of the gear unit.

Values of load capacities are adopted in such a way that growth factor of torque is calculated as follows $[1,2]$ :

$$
q_{T}=q_{L}^{3}=1,24^{3}=2
$$

which approximately corresponds to the maximum value of service factor $f_{B}$ (where $q_{T}-$ growth factor of torque, $q_{L}$ - growth factor of linear dimensions, shaft height in this case). 
Considering the application area of universal gear unit (Figure 3), it is evident the gear unit is mostly used in the area $\left(T_{N}-T_{N} / f_{B}\right)$.

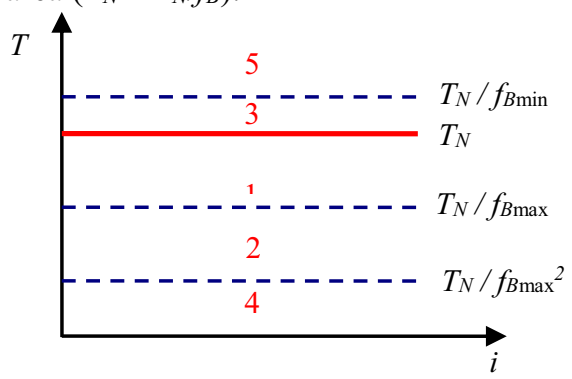

Fig. 3. Schematic review of application field of universal gear reducer according to torque values: 1 - the main area, 2 - the additional area, 3 - critical area (used only for short drives), 4 - the area where the reducer is oversized (not economically used) and 5 - critical area where breakdown of the reducer happens immediately.

Defining the values of output torque within the family of universal gear reducers in such a way, for the approximately same gear ratio interval, provides full coverage of market demands for output torque. In this way the main application area of gear unit is covered by the family of gear reducers (Fig. 4).

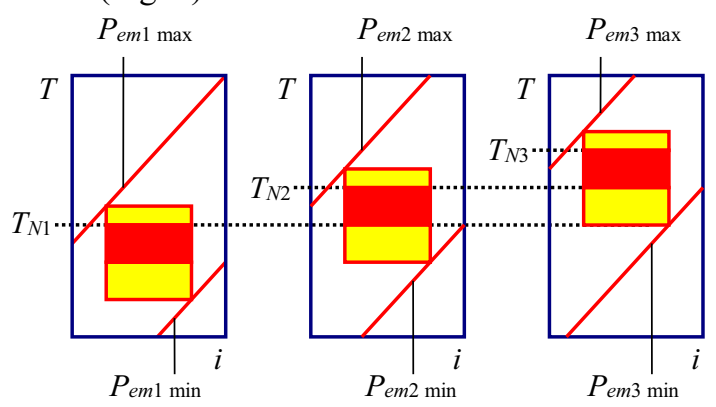

Fig. 4. Position of the main application areas of universal gear reducers within three neighbour sizes of gear unit.

However, the main application area of only one size of gear unit should be considered with using two sets of gear pairs. One set of gear pair has large load capacity and lower gear ratio (Figure 5, area 1), and the other set has smaller load capacity with higher gear ratio (Figure 5, area 2). It is clear that the gear unit with smaller load capacity will be cheaper since the gears have smaller module and smaller production costs. Considering higher gear ratio, for slightly lower capacity, three-stage gear reducer will be much cheaper than four-stage gear reducer with higher load capacity (shaded area, Fig. 5) [9, 10].

If it is required smaller load capacity and higher gear ratio, universal three-stage gear reducer can be much improved. For example three-stage gearbox with highest gear ratio of 100 , can be modified and produced with some smaller load capacity, but with much higher gear ratio, for instance $112,125,140,160,180,200,224,250$, or even 280 . In such way, it is offered cheaper solution than four-stage gear ratio, with the same values of gear ratio. This approach increases the offer of cheaper solutions, but also it should be emphasized that in the area of smaller capacities and lower gear ratio than 100, it can be also offered lower cost solution. This is the space where smaller manufacturers of gear units can find their place for existence on the market. 
Table 1. Examples of nominal torque capacities and highest gear ratio for two-stage gear reducer of different manufacturers.

\begin{tabular}{|c|c|c|c|}
\hline $\begin{array}{c}\text { Axis height } \\
h, \mathrm{~mm}\end{array}$ & $\begin{array}{c}\text { Designation of gear } \\
\text { unit }\end{array}$ & $\begin{array}{l}\text { Nominal output } \\
\text { torque, } T_{N}, \mathbf{N m}\end{array}$ & $\underset{i_{\max }}{\text { Max gear ratio }}$ \\
\hline \multicolumn{4}{|c|}{ Manufacturer: SEW } \\
\hline 90 & R 27 & 130 & 28,37 \\
\hline 90 & R 37 & 200 & 28,32 \\
\hline 115 & R 47 & 240 & 33,79 \\
\hline 115 & R 57 & 450 & 26,31 \\
\hline \multicolumn{4}{|c|}{ Manufacturer: Siemens-Flender } \\
\hline 90 & Z28 & 145 & 51,35 \\
\hline 90 & Z38 & 210 & 44,12 \\
\hline \multicolumn{4}{|c|}{ Manufacturer: Nord - NORDBLOC } \\
\hline 90 & SK 272 & 145 & 64,75 \\
\hline 90 & SK 372 & 181 & 51,23 \\
\hline 115 & SK 472 & 334 & 65,56 \\
\hline 115 & SK 572 & 431 & 51,7 \\
\hline \multicolumn{4}{|c|}{ Manufacturer: Rossi - ES07 } \\
\hline 90 & MR 2I 2 & 156 & 28,9 \\
\hline 90 & MR 2I 3 & 195 & 31,1 \\
\hline 115 & MR 2I 4 & 286 & 31,4 \\
\hline 115 & MR 2I 5 & 398 & 23,4 \\
\hline \multicolumn{4}{|c|}{ Manufacturer: Rossi - E04 } \\
\hline 90 & MR 2I 40 & 75 & 22,1 \\
\hline 90 & MR 2I 41 & 74 & 13,3 \\
\hline 106 & MR 2I 50 & 143 & 22,3 \\
\hline 106 & MR 2I 51 & 200 & 18,3 \\
\hline 132 & MR 2I 63 & 302 & 24,3 \\
\hline 132 & MR 2I 64 & 401 & 19 \\
\hline 160 & MR 2I 80 & 650 & 24,5 \\
\hline 160 & MR 2I 81 & 730 & 20,1 \\
\hline 195 & MR 2I 100 & 1100 & 23,4 \\
\hline 195 & MR 2I 101 & 1230 & 19,3 \\
\hline 236 & MR 2I 125 & 2280 & 24,3 \\
\hline 236 & MR 2I 126 & 2560 & 19 \\
\hline
\end{tabular}


Table 2. Examples of nominal torque capacities and highest gear ratio for three-stage gear reducer of different manufacturers.

\begin{tabular}{|c|c|c|c|}
\hline $\begin{array}{l}\text { Axis height } \\
\quad h, \mathrm{~mm}\end{array}$ & $\begin{array}{c}\text { Designation of gear } \\
\text { unit }\end{array}$ & $\begin{array}{l}\text { Nominal output } \\
\text { torque, } \boldsymbol{T}_{N}, \mathrm{Nm}\end{array}$ & $\underset{i_{\max }}{\text { Max gear ratio }}$ \\
\hline \multicolumn{4}{|c|}{ Manufacturer: SEW } \\
\hline 90 & R 27 & 130 & 135,09 \\
\hline 90 & R 37 & 200 & 134,82 \\
\hline 115 & $\mathrm{R} 47$ & 300 & 176,88 \\
\hline 115 & R 57 & 450 & 186,89 \\
\hline \multicolumn{4}{|c|}{ Manufacturer: Siemens-Flender } \\
\hline 90 & D28 & 142 & 207,96 \\
\hline 90 & D38 & 224 & 191,75 \\
\hline \multicolumn{4}{|c|}{ Manufacturer: Nord - NORDBLOC } \\
\hline 90 & SK 273 & 137 & 330,9 \\
\hline 90 & SK 373 & 214 & 238,68 \\
\hline 115 & SK 473 & 336 & 309,58 \\
\hline 115 & SK 573 & 465 & 309,58 \\
\hline \multicolumn{4}{|c|}{ Manufacturer: Rossi - ES07 } \\
\hline 90 & MR 3I 2 & 155 & 126 \\
\hline 90 & MR 3I 3 & 230 & 136 \\
\hline 115 & MR 3I 4 & 350 & 181 \\
\hline 115 & MR 3I 5 & 500 & 178 \\
\hline \multicolumn{4}{|c|}{ Manufacturer: Rossi - E04 } \\
\hline 90 & MR 3I 40 & 88 & 92,8 \\
\hline 90 & MR 3I 41 & 98 & 74,4 \\
\hline 106 & MR 3I 50 & 160 & 130 \\
\hline 106 & MR 3I 51 & 224 & 107 \\
\hline 132 & MR 3I 63 & 335 & 142 \\
\hline 132 & MR 3I 64 & 450 & 111 \\
\hline 160 & MR 3I 80 & 670 & 154 \\
\hline 160 & MR 3I 81 & 900 & 126 \\
\hline 195 & MR 3I 100 & 1320 & 144 \\
\hline 195 & MR 3I 101 & 1800 & 118 \\
\hline 236 & MR 3I 125 & 2650 & 150 \\
\hline 236 & MR 3I 126 & 3550 & 117 \\
\hline
\end{tabular}




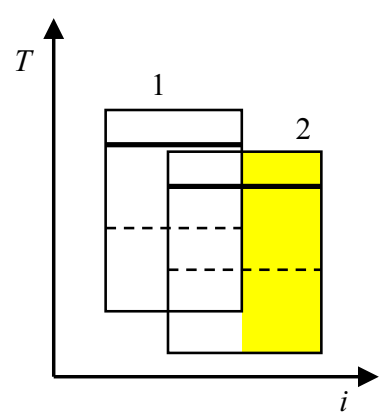

Fig. 5. Characteristic application areas of three-stage gear unit with larger torque capacity (1) and with smaller torque capacity, but higher gear ratio (2). Shaded area represents less expensive solution.

Some large manufacturers are trying to create so-called intermediate size of gear units and thus offer a cheaper solution (Figure 6, Table 3). With this additional size, they increase the number of gear unit components they must produce (housings, gears, shafts, bearings, etc.), so this procedure can not be considered as favourable as the application of housing with two sets of gear pairs.

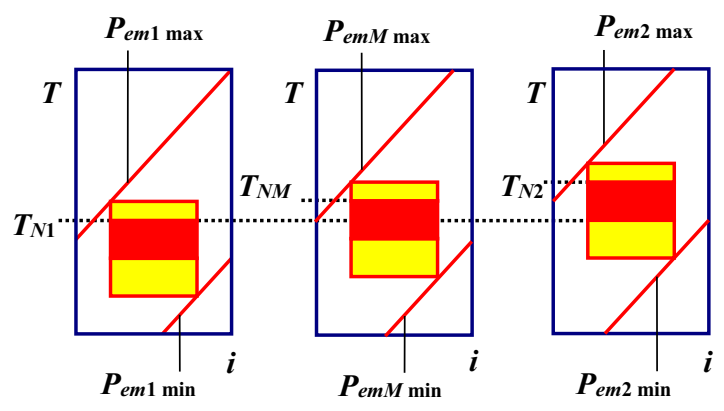

Fig. 6. Schematic review of torque and gear ratio areas that are covered by certain sizes of gear reducers by introducing additional size.

Table 3. Examples of providing additional size of two-stage gear reducer of different manufacturers.

\begin{tabular}{|c|c|c|c|}
\hline $\begin{array}{c}\text { Axis height } \\
\boldsymbol{h}, \mathbf{m m}\end{array}$ & $\begin{array}{c}\text { Designation of gear } \\
\text { unit }\end{array}$ & $\begin{array}{c}\text { Nominal output } \\
\text { torque, } \boldsymbol{T}_{\boldsymbol{N}}, \mathbf{N m}\end{array}$ & $\begin{array}{c}\text { Max gear ratio } \\
\boldsymbol{i}_{\max }\end{array}$ \\
\hline \multicolumn{4}{|c|}{ Manufacturer: SEW } \\
\hline 115 & R 57 & 450 & 26,31 \\
\hline $\mathbf{1 3 0}$ & R 67 & $\mathbf{5 8 0}$ & $\mathbf{2 8 , 1 3}$ \\
\hline 140 & R 77 & 705 & 23,37 \\
\hline \multicolumn{4}{|c|}{ Manufacturer: Nord - NORDBLOC } \\
\hline 115 & SK 572 & 431 & 51,7 \\
\hline $\mathbf{1 3 0}$ & SK 672 & $\mathbf{5 3 4}$ & $\mathbf{6 4 , 1 8}$ \\
\hline 140 & SK 772 & 858 & 62,32 \\
\hline
\end{tabular}

Using this approach, almost the same load capacity can be obtained as with second gear pair of gear reducer with two sets of gear pairs. Production costs will be a little lower, but production will be increased because of introducing additional size and keeping in stock the components of all sizes of gear reducer. Large manufactures do not have this problem since 
they have large production and large stocks. However, if some small manufacturers want to be competitive, they have to produce every special dimension of the additional gears, but sometimes they are not able to provide absolute interchangeability.

\section{Conclusions}

The using of two gear sets of gear pairs within the same gear reducer housing is very justified procedure. Production is a little bit complicated and it is required larger stock for all necessary gears, but only in this way it is always possible to offer cheaper solution and in that way remove the possible advantage of competitive solution. In order to increase the offer of their reducer, large manufacturers often introduce additional size of gear unit. Small manufacturers try to compete with them and stay at the market by offering cheaper solution with high gear ratio and smaller torque capacity, so they offer gear units with one stage less.

This paper is part of a research on project "Research and Development of a New Generation of Wind Generators of High Energy Efficiency" TR 35005, supported by the Ministry of Education and Science, Republic of Serbia.

\section{References}

1. S. Kuzmanović, Universal Gear Reducers with Cylindrical Gears (in Serbian), (University of Novi Sad, Faculty of Technical Sciences, Novi Sad, 2009)

2. S. Kuzmanović, M. Rackov, Proc. of the Int. Conf. on Power Transmission - BAPT, Kallithea, $G R, 145$ (2009)

3. Rossi, E04 - Coaxial Gear Reducers and Gearmotors, 4002BRO.ECO-en 1210 HQM (2015)

4. Rossi, ES07 - Coaxial Gearmotors, STANDARDFIT, 4063BRO.EST-en 1210 HQM (2015)

5. ***https://www.lenze.com/fileadmin/lenze/documents/de/catalogue/CAT_GKR_GKS_GSS_MF _15593792_de_DE.pdf, Accesed 01.03.2017

6. ***http://download.sew-eurodrive.com/download/pdf/16997611_G01.pdf, Accesed 10.03.2017

7. NORD Drivesystems, Standard Helical Gearboxes, G (2012)

8. ***https://www.automation.siemens.com/md-static/D87-1_en_2011.pdf, Accesed 01.02.2017

9. S. Kuzmanović, M. Vereš, M. Rackov, T. FAMENA 38(1), 77 (2014)

10. M. Rackov, Conceptions of Development of Universal Gear Reducers (Ph.D. thesis in Serbian), (University of Novi Sad, Faculty of Technical Sciences, 2013)

11. S. Kuzmanović, M. Rackov, I. Knežević, M. Vereš, Proc. of the Int. Symp. on Machine and Industrial Design in Mechanical Engineering - KOD, Balatonfured, HU, 73 (2016)

12. M. Rackov, I. Knežević, S. Kuzmanović, M. Čavić, M. Penčić, S. Ianici, Proc. of the Int. Conf. on Mechanical Engineering Technologies and Applications - COMETa, East Sarajevo, BA, 301 (2016) 